\title{
Brexit and What It Means For REACH and CLP
}

\author{
Hartmut Scheidmann and Matthias Kottmann*
}

This article examines the consequences of the so-called Brexit in view of the EU regulatory regime on chemicals. Two years ago, a Member State leaving the EU was regarded by most as a merely theoretical scenario. Yet, following the referendum of 23 June 2016, actors both in the political and economic sphere have to adapt quickly in order to master imminent challenges. To address these challenges, this paper will first outline the basic legal framework that governs the UK's withdrawal from the EU and the development of this procedure up to now. In a second step, it will examine specific problems in view of EU chemicals regulation while providing some ideas as regards possible solutions.

\section{Introduction}

Until Summer 2016, a Member State leaving the EU was regarded by most as a merely theoretical possibility. This is probably true even for fervent supporters of such an idea. Rather, the course of European integration seemed to be set towards 'an ever closer Union' - as it is put in Article 1 of the Treaty on European Union (TEU). It is thus no wonder that the implications of such a scenario have not been at the centre of scholarly attention for quite some time. Yet, following the referendum of 23 June 2016, actors both in the political and economic sphere have to adapt quickly in order to master imminent challenges that have been described by some as analogous to 'unscrambling eggs.'

As it is impossible to name, let alone think through all the legal questions resulting from Brexit, this ar-

\section{DOI: $10.21552 / \mathrm{icrl} / 2018 / 1 / 4$}

* Hartmut Scheidmann, Partner at Redeker Sellner Dahs, Berlin. For correspondence: <scheidmann@redeker.de> Dr Matthias Kottmann, Senior Associate at Redeker Sellner Dahs, Berlin. For correspondence: <kottmann@redeker.de>

1 David Miliband, 'Tory Brexit policy is chaotic: the fightback against this stitch-up must begin at once' The Guardian (London, 12 August 2017).

2 See, inter alia, Vassilios Skouris, 'Rechtliche Vorgaben für den Austritt aus der EU' (2016) EuZW 806; Jean-Paul Jacqué, 'Brexit (Une analyse factuelle)' (2016) RTD eur 689; Patrick J Birkinshaw and Andrea Biondi, Britain Alone! The Implications and Consequences of United Kingdom Exit from the EU (Kluwer Law International 2016); Alexander Thiele 'Der Austritt aus der EU Hintergründe und rechtliche Rahmenbedingungen eines "Brexit" (2016) EuR 281; Paul Craig 'Brexit: A Drama in Six Acts' (2016) EL Rev 447; Catherine Barnard 'The practicalities of leaving EU' (2016) EL Rev 484. ticle will proceed in a rather modest manner and focus on identifying certain key topics under Regulation(EC) No 1907/2006 (REACH Regulation) and Regulation (EC) No 1272/2008 (CLP Regulation). Accordingly, it will first portray the basic legal framework that governs the UK's withdrawal from the EU and the development of this procedure up to now (Section II). Following this, it will then examine specific problems in view of the EU regulatory regime on chemicals while providing some ideas as regards possible solutions (Section III).

\section{Legal background}

\section{The Article 50 Cliff Edge}

The process of leaving the EU is set out in Article 50 TEU. According to this provision, any Member State may decide to withdraw from the Union in accordance with its own constitutional requirements. If a Member State decides to do so, it shall notify the European Council of its intention to leave. Then, the EU shall negotiate and conclude an agreement with that state, setting out the arrangements of withdrawal while taking account of the framework of the future relationship.

These are rather rudimentary instructions for an immensely complicated endeavour. It thus comes as no surprise that there are many unanswered legal questions. ${ }^{2}$ Article 50 TEU is crystal clear, however, in at least one respect: If a Member State notifies the European Council of its intention to leave, it triggers 
a two-year deadline upon expiry of which all EU law ceases to apply to the State in question. It is of course possible to set a different exit date in the withdrawal agreement and/or to prolong the deadline. Yet, this requires an agreement between the State in question and the European Council and, thus, depends on the unanimous consent of all remaining Member States. Article 50(3) TEU puts this in the following words:

'The Treaties shall cease to apply to the State in question from the date of entry into force of the withdrawal agreement or, failing that, two years after the notification referred to in paragraph 2, unless the European Council, in agreement with the Member State concerned, unanimously decides to extend this period.'

The effect of this provision is obvious: Once the exit mechanism is triggered, negotiating the withdrawal agreement takes place in the shadow of the twoyear deadline and, thus, under enormous time pressure. In the eyes of the drafters of Article 50 TEU, this was meant to prevent abuse of the Article 50 procedure and to serve as a disincentive against using it at all. ${ }^{3}$ It is thus not without reason that Article 50(3) TEU is sometimes referred to as a 'cliff edge'.

The UK submitted its notification under Article 50 TEU on 29 March 2017. This means that normally EU law would cease to apply to the UK on 30 March 2019, o0:0oh (CET-Summer). However, in March 2018 the negotiating teams agreed on a transition period which will run until 31 December 2020 during which Union law shall be applicable, in principle, in the UK. ${ }^{5}$ Yet, economic actors should not blindly rely on that transition period: As Michael Barnier ${ }^{6}$ has said: 'Nothing is agreed until everything is agreed'. Hence, it cannot be ruled out that the negotiations will fail and that all EU law will cease to apply to the UK on 30 March 2019, o0:0oh (CET-Summer) respectively 29 March 2019, 23:00 h (GMT-Summer).

Regardless of the point in time at which Brexit will happen and in which EU law will become inapplicable, for economic operators, these steps will entail three important consequences: Firstly, any rights they enjoy under EU law cannot be invoked, as such, in the UK. Secondly, all institutions, agencies and bodies of the EU lose their competence to act in the territory of the UK. And thirdly, any reference made in an EU act to the territory of a 'Member State', the 'Community', the 'Union' or the 'European Econom- ic Area' (EAA) ceases to apply with respect to the UK. This is of utmost importance because under most regulatory regimes only companies established in the EU have access to the European Single Market. We will pick up that aspect with regard to REACH and CLP in a detailed discussion below.

\section{The Repeal Bill}

A considerable amount of all law applicable in the Member States is in fact of EU origin. Replacing it with 'autonomous' national law would probably take decades. In order to avoid a regulatory vacuum on exit day, the UK Government has hence introduced, and the UK Parliament (House of Commons), has adopted, the European Union (Withdrawal) Bill - also referred to as 'the Great Repeal Bill'.

The aim of this draft statute is to retain the bulk of EU-related law as national law, in order to give the UK legislator the time necessary to decide which rules to keep and which ones to amend. More precisely, it foresees that on exit day (a) domestic legislation derived from EU law remains in force and (b) EU legislation as it stands becomes part of domestic law. It furthermore gives Ministers of the Crown the power to 'remedy' any 'deficiencies' arising out of this legislative technique (informally known as 'Henry VIII clauses'), eg by adopting regulations that entrust government agencies with tasks previously held by institutions, agencies or bodies of the EU. ${ }^{8}$ As an outside observer, one may certainly wonder to what extent such an approach, ie first incorporating all EU

3 See Piet Eeckhout and Eleni Frantziou, 'Brexit and Article 50 TEU: A Constitutionalist Reading' (2017) CML Rev 54: 695, 706.

5 European Commission, 'Press statement by Michel Barnier following the latest round of Article 50 negotiations' (19 March 2018) available at $<$ http://europa.eu/rapid/press-release STATEMENT-18-2161_en.htm> accessed 24 March 2018; see Art 122 paras 1 and 3 of the 'Draft Agreement on the withdrawal of the United Kingdom of Great Britain and Northern Ireland from the European Union and the European Atomic Energy Community', available at <https://ec.europa.eu/commission/publications/ draft-agreement-withdrawal-united-kingdom-great-britain-and -northern-ireland-european-union-and-european-atomic-energy -community-0_en> accessed 24 March 2018.

6 Head of the EU Commissions's Task Force for the Brexit-negotiations.

7 European Commission, 'Press statement by Michel Barnier following the latest round of Article 50 negotiations' (19 March 2018) available at <http://europa.eu/rapid/press-release _STATEMENT-18-2161_en.htm> accessed 24 March 2018

8 European Union (Notification of Withdrawal) Act 2017 Ch 91. 
law and then giving the executive far-reaching legislative powers to change it, serves the proclaimed goal of 'giving the citizens of the UK back control over their laws'. 9

It is important to note, however, that the Repeal Bill will not prevent most of the negative consequences for economic actors mentioned above: Rights acquired under EU legislation will be transformed into rights under the national law of the UK. They will thus only be recognised in the UK but not in the EU-27. Furthermore, the Repeal Bill will only offer limited regulatory stability as retained law could be amended unilaterally by the UK legislature - or even by executive regulation - at any time. In addition, economic actors cannot turn to EU institutions in order to have their rights enforced. They must instead rely on the respective national bodies designated under the Repeal Bill. Most importantly, transforming EU legislation into national law cannot change the fact that, on exit day, EU law as such ceases to apply to the UK. Economic operators based in the UK will therefore become third-state actors that do not enjoy, in principle, the same rights as their competitors in EU Member States.

9 The Rt Hon Theresa May, 'The government's negotiating objectives for exiting the EU: PM speech' (17 January 2017) Prime Minister's Office, 10 Downing Street, available at $<$ https://www .gov.uk/government/speeches/the-governments-negotiating -objectives-for-exiting-the-eu-pm-speech> accessed 30 August 2017.

10 See, Carl Baudenbacher, 'After Brexit: EEA plus as a solution for the UK?' (2016) NZKart 498, 498.

11 Department for Exiting the European Union, 'Legislating for the United Kingdom's withdrawal from the European Union' (March 2017) White Paper Cm 9446, 7.

12 ibid, 35.

13 European Council, 'European Council (Art 50) guidelines following the United Kingdom's notification under Article 50 TEU' (29 April 2017) available at <http://www.consilium.europa.eu/en/ press/press-releases/2017/04/29-euco-brexit-guidelines/> accessed 30 August 2017.

14 The Rt Hon David Davis MP, Department for Exiting the European Union, 'The United Kingdom's exit from and new partnership with the European Union' (February 2017) Cm 9417, 35.

15 Department for Exiting the European Union, 'Continuity in the availability of goods for the EU and the UK - position paper' (21 August 2017) 3.

16 ibid, 7

17 The Swiss regulatory framework on chemicals is closely aligned with REACH. Yet there is no mutual recognition of registrations and authorisations. The EU and Switzerland do have concluded a sector specific agreement regarding biocides. However, this agreement does not provide for 'automatic' mutual recognition but rather for simplified authorisation procedures. See $<$ https:// www.anmeldestelle.admin.ch/chem/en/home/themen/recht -wegleitungen/chemikalienrecht/biozidprodukteverordnung.html $>$ accessed 30 August 2017.

\section{3. 'Brexit Means Brexit' - Really?}

Many of these consequences could in theory be avoided by what has been called a 'soft Brexit'. Leaving the EU does not necessarily mean leaving the Single Market. In that regard, two models come to mind: First, the UK could seek to remain part of the European Economic Area (EEA) which basically extends the EU regulatory acquis to Iceland, Liechtenstein and Norway. ${ }^{10}$ Second, it could participate in the Single Market on the basis of bilateral agreements - this is the so-called 'Swiss model'.

Yet, any such outcome seems unlikely at present: The UK Government is determined to 'take control of its laws.'11 Submitting to the whole or to important parts of the EU acquis would be hard to reconcile with this goal. Consequently, the White Paper published by the UK Government in February 2017 plainly states: 'We will not be seeking membership of the Single Market'. ${ }^{12}$ The EU-27, on the other hand, have made very clear that the Single Market is indivisible and that they will not allow the UK to engage in 'cherry picking' individual elements. ${ }^{13}$ There is, of course, much lobbying in that regard by various sectors of the economy. Yet, presently, both sides seem firmly entrenched in their positions.

Instead, the UK seeks to conclude an 'ambitious and comprehensive free trade agreement' with the EU. ${ }^{14}$ Recently, it has added that it wants mutual recognition to play an important part in that agreement. For instance, in a position paper of August 2017, the UK Government has stated that, 'where businesses have undertaken compliance activities prior to exit, they should not be required to duplicate these activities.' ${ }^{15}$ Therefore, it 'wants to ensure that any approvals, registrations, certificates and authorisations issued by a third party (whether a private entity or a public agency) prior to exit should continue to be recognised as valid by both markets after the UK's withdrawal.' ${ }^{16}$ It is important to note, however, that the scope of this proposal seems to be limited to activities undertaken before Brexit. Mutual recognition of registrations or authorisations issued after Brexit appears to be out of question. It may be added that mutual recognition of registrations and authorisations in the field of REACH would be unprecedented, as the EU does not even have such an agreement in relation with Switzerland. ${ }^{17}$ Finally, it is highly uncertain whether the UK's proposal will be successful. The EU-27 have explicitly and repeat- 
edly stated that the four freedoms of the Single Market are indivisible and there can be no 'cherry picking. ${ }^{18}$

\section{Consequences for REACH and CLP}

At this stage, it should be clear that Brexit - understood here as the point in time where either the UK leaves the EU without transition rules or where the transition period expires - will have far-reaching consequences for economic actors both in the UK and in the EU-27. It is of course impossible to foresee let alone think through - all the possible repercussions. Nevertheless, the following section will identify certain key problems under the REACH and CLP Regulation and, where appropriate, suggest some viable solutions.

\section{Registration}

\section{a. Basic Principles}

Registration of substances is a central element of REACH. According to Article 5 of the REACH Regulation, substances shall not, in principle, be manufactured or placed on the market unless they have been registered. However, the right (and the duty) to register substances as set out in Title II of the REACH Regulation is reserved for EU (or EEA) companies. This is so because, according to the definitions contained in Article 3(4) to (11) of the REACH Regulation, a 'registrant' of a substance is necessarily a person established in the EU (or the EEA). Third-country companies therefore cannot register substances under the REACH Regulation. If they want to place substances on the European market, they need to rely on persons established in the EU: They must either appoint an Only Representative that fulfils the duties of a registrant on their behalf or sell their substances to EU customers that are themselves registered as importers. The former option, however, is only available to manufacturers of substances or producers of articles and, thus, not to distributors.

\section{b. Impact On UK Registrants}

As long as the UK is a Member State and as long as the transition period in its draft arrangement lasts,
UK companies will be subject to all rights and duties arising from the REACH Regulation. Namely, they have to observe the deadline set out in Article 23(3) of the REACH Regulation for registering low-volume substances. Otherwise, they will not be able to manufacture or import such substances from 1 June 2018 on.

However, on exit day, all registrations held by persons established in the UK will become invalid under the REACH Regulation. As shown before, this is due to the fact that third-country companies cannot be registrants. Investments made in order to obtain such registrations will, in principle, be lost. This is problematic in particular with regard to registrations that were only submitted shortly before exit day.

Inside the UK, registrations may well be retained in accordance with the Withdrawal Bill. But that will provide small comfort for companies that have spent considerable sums in order to be able to market substances across Europe. ${ }^{19}$ Furthermore, it should be noted that the REACH Regulation does not foresee the possibility to trade registrations. According to Article 22(1) lit. (a) of the REACH Regulation, registrants can (and must) update their registration data in case their legal identity has changed..$^{20}$ This means that legal entities established in the UK could be moved to an EU-27 Member State taking their registrations with them. It is not possible, however, to transfer registrations from one registrant to another.

Without registration, UK businesses will not themselves have access to the European market. As regards manufacturers and producers, they can appoint an Only Representative in the EU - which, of course, involves additional costs. Otherwise, EU customers of UK companies will have to register as importers and thus themselves bear the respective costs.

18 See European Council Guidelines EUCO XT 2004/17, Core Principle no 1; European Council, 'Supplementary directives for the negotiation of an agreement with the United Kingdom of Great Britain and Northern Ireland setting out the arrangements for its withdrawal from the European Union' XT 21004/18 ADD 1 REV 2, para 10; European Council, Guidelines EUCO XT 20001/18, para 7 .

19 There are estimates that, on exit day, UK companies will have spent around 271.000.000 EUR on registrations. See, House of Commons, Environmental Audit Committee, 'The Future of Chemicals Regulation after the EU Referendum' (29 April 2017) HC 912, 5 .

$20 \mathrm{Cf}$ ECHA, 'Practical guide 8: How to report changes in identity of legal entities' (15 April 2010) available at <https://echa.europa .eu/documents/10162/13643/pg_8_legal_entity_change_en.pdf> accessed 31 August 2017. 
In some cases, EU customers may therefore choose an alternative supplier which is established in the EU rather than face the additional burden of being a registrant. Against this background, there are indications that quite a few UK registrants are considering moving operations to an EU Member State in order to preserve their business in the EU. ${ }^{21}$

\section{c. Impact On EU Customers}

After Brexit, EU customers of UK manufacturers/importers cannot be considered downstream users within the meaning of Article 3(13) of the REACH Regulation. Instead, as their suppliers will have lost their legal status under the REACH Regulation, they will be regarded as persons responsible for importing substances into the EU and, hence, as importers in terms of Article 3(11) of the REACH Regulation. This can only be avoided if their supplier has appointed an Only Representative in the EU-27 (or in the EEA) in due time. Once they are regarded as importers, EU companies are obliged to register substances themselves. Without registration, they will not be able to place substances on the market. This principle of 'no data, no market' is set out in Article 5 of the REACH Regulation.

There is, however, a dilemma: On the one hand, the importers-to-be must have their registrations completed on exit day in order to avoid disruption of their businesses. On the other hand, according to the letter of the REACH Regulation, they are currently not entitled to submit registrations. Under Article 6 of the REACH Regulation, this can only be done by an importer (or a manufacturer). Yet, EU customers of UK suppliers are not considered importers as long as the UK is still an EU Member State.

Two possible solutions come to mind: First, the text of the REACH Regulation could be amended in order to allow EU importers-to-be to submit registrations before exit day and/or to enjoy transitional periods for registration after exit day. This solution depends, however, on the willingness - and on the speed - of the Union legislature. Second, as a lessthan-ideal solution, EU customers could submit registrations pretending to act as importers. ECHA does not examine whether registrants actually import or intend to import the substances in question. Further-

21 See (n 19) 5. more, as completing a registration is time-intensive and market conditions tend to fluctuate, it is not unusual for an importer to submit registrations 'in stock'. Consequently, EU customers of UK manufacturers/importers should therefore closely monitor the ongoing Brexit negotiations and react in a timely manner.

\section{d. Impact On Non-EU Manufacturers and Only Representatives}

To date, a considerable number of third-country manufacturers rely on Only Representatives established in the UK in order to have access to the Single Market. After Brexit, this route will be barred, as according to Article 8 of the REACH Regulation, an Only Representative must be established in the EU (or the EEA). In that way, Brexit will even have an impact on companies established outside the EU.

Consequently, non-EU manufacturers should ask their UK-based Only Representatives to set up an establishment in an EU-27 Member State. Many Only Representatives will probably do so on their own initiative. In the alternative, non-EU manufacturers will have to exchange their Only Representative. This does not pose important problems as far as the REACH Regulation is concerned and can be done via the online system REACH IT, provided that the respective Only Representative cooperates. Yet, there may be some contractual hurdles depending on the specific terms agreed between the parties.

It follows from the above that Brexit poses a particular challenge for UK-based Only Representatives: They may be able to continue their activities in the UK in accordance with the Withdrawal Act. Yet, after exit day, they cannot offer their clients access to the Single Market any more. Consequently, Only Representatives established in the UK should consider shifting their establishment - or set up an additional establishment - in an EU-27 Member State.

\section{e. Impact on Joint Submissions, SIEF and Consortia}

Specific problems arise with regard to joint submissions. According to Article 11 of the REACH Regulation, a substance intended to be manufactured or imported by several companies shall, in principle, be registered only once. Registrants thus have to choose a lead registrant that effects a full registration while 
all the others submit, in principle, only additional information. However, a lead registrant established in the UK will inevitably lose its position on exit day. EU companies should therefore verify whether they participate in a joint registration where the lead registrant is established in the UK. If that is the case, steps should be taken in order to choose another lead registrant that is established in the EU-27 (or the EEA). The REACH Regulation does not prevent the change of a lead registrant. Consequently, co-registrants can agree to transfer the lead role to another registrant at any point. This process may however prove time-consuming, as it requires consensus among all the actors involved. The exact procedure to effect such a change in REACH IT is described in ECHA's Q\&A. ${ }^{22}$

In contrast, Brexit will not necessarily terminate the membership of UK actors in a substance information exchange forum (SIEF). According to Article 29(1) of the REACH Regulation, registrants of a substance, potential registrants, downstream users and third parties who have submitted information to ECHA or whose information is held by ECHA shall be participants in a SIEF. Following exit day, UK companies cannot participate in a SIEF as registrants, potential registrants or downstream users because this requires establishment in the EU. ${ }^{23}$ Consequently, they are no longer subject to the data-sharing obligation incumbent on (potential) registrants. Yet, UK actors may still participate as 'third parties' within the meaning of Article 29(1) of the REACH Regulation if their information is held by ECHA. They will hence, in principle, remain bound and entitled by the respective SIEF or data sharing agreement. Namely, the other SIEF members will be allowed to use data stemming from UK actors while the latter will participate in the respective revenues.

The situation differs in the case of registration consortia. These are joint submissions based on a contractual agreement between the respective companies rather than on the 'pure' provisions of the REACH Regulation. The impact of Brexit therefore depends on the specific terms of the consortium agreement. Typically, such agreements provide for their termination or a right of withdrawal in the event that the status as a manufacturer or importer is lost. Parties to a consortium should therefore verify whether one or several members are established in the UK and, if that is the case, review the clauses of their consortium agreement in due time.

\section{Classification And Labelling}

In the event of the Brexit, all actors in the UK supply chain (manufacturers, importers, downstream users, and distributors) cease to be obliged to classify and label products under the CLP. According to the statutory definition of these actors in Article 3, Nos. 15, 17, 19 and 20 of the CLP Regulation, said obligation is subject to the condition that they are established within the Community. In practice, however, UK actors will have to continue classifying and labelling their substances and mixtures in order to be able to appropriately supply their customers in the EU according to demand. For EU customers, by contrast, nothing much will change. They will continue to be subject to the original classification and labelling obligation. However, compliance with these obligations may become more difficult if against their expectations they do not receive a safety data sheet or properly packaged products from their UK suppliers.

Likewise, UK manufacturers/importers will no longer be obliged to notify the Agency of the classification resulting from the classification and labelling inventory maintained by ECHA (Article 40 and 42 CLP). In cases in which a UK manufacturer/importer is the lead registrant under a mutual agreement on an agreed entry, as required under $\mathrm{Ar}$ ticle 41 of the CLP Regulation, all parties involved would have to ensure that the lead registrant is exchanged in good time before the exit day.

For EU customers of UK manufacturers/importers, things will change with regard to classification and the labelling inventory. Henceforward, they will become importers of the substances and/or mixtures procured and will themselves be subject to the notification obligation under Article 40 of the CLP Regulation. Again, the same dilemma arises as with regard to registration: the obligation of one party ceases to exist at exactly the same moment it is imposed onto another party. Here, too, transitional periods should be discussed in the Brexit negotiations. If in doubt, at least the one-month period under $\mathrm{Ar}$ -

22 See ECHA, 'REACH-IT Joint Submissions - Q\&A' (ECHA, 25 April 2018) <https://echa.europa.eu/support/qas-support/browse/-/qa/ 70Qx/view/ids/0380> accessed 31 August 2017.

23 See Arts 3(7) icw 3(9) and (11) and Art 3(13) of the REACH Regulation. 
ticle 40 paragraph 3 of the CLP Regulation could be applied mutatis mutandis.

\section{Communication Within The Supply Chain}

After Brexit, manufacturers and importers from the UK will no longer be subject to the communication obligations under Article 31 and 32 of the REACH Regulation. For, according to the definition of suppliers under Article 3 No. 32 of the REACH Regulation, the addressees of these obligations - the suppliers of substances and mixtures - are manufacturers, importers, downstream users, or distributors, who are all required to be established in the EU (Article 3 Nos. 9, 11, 13 and 14 REACH).

Consequently, UK suppliers are not obliged to provide their EU customers with a safety data sheet for dangerous substances. This, however, is only the statutory side. UK suppliers are certainly well advised for practical reasons to continue to provide a safety data sheet 'voluntarily' if they want to keep their EU customers and be able to deliver to them according to demand. Moreover, the supply contracts very often foresee the provision of safety data sheets as a binding commitment. This contractual obligation will not be affected in the event of Brexit, unless it is subject to the existence of the statutory obligation under the REACH Regulation. Therefore, all EU customers are advised in their own interest to review their supply contracts with UK suppliers in this respect and 'subsequently improve' them where necessary.

The same applies accordingly to the communication obligations relating to SVHC in products under Article 33 REACH. After Brexit, UK suppliers of products will no longer be subject to these legal obligations because they will no longer be suppliers as defined by law. Consequently, their EU customers will have no statutory claim to receive information on the content of SVHC in products. However, UK suppliers are well advised to continue providing this information 'voluntarily' so as to not jeopardise the supply relationship. EU customers should however make sure that this is sufficiently supported by contractu-

24 Even if the definition of 'registrant' in Art 3 no 7 REACH is not clear in this respect, see above under 'SIEF and data sharing'. al arrangements. Only if this is the case, can EU customers meet their own communication obligations in the supply chain, ie to report SVHC in articles under Article 7 paragraph (2) et seqq of the REACH Regulation. The last mentioned notification obligations newly arise in the case of EU customers because, upon the Brexit, the latter will turn into the importers of the articles.

This situation is comparable to communication relating to uses and their safety under Article 37 et seqq of the REACH Regulation. UK actors will no longer be subject to this obligation. But since their EU customers will have then become importers and will be subject themselves to registration obligations they should make sure by contractual arrangements that they will continue to receive the corresponding information.

Where EU customers as downstream users so far had own uses that were not mentioned in the registrations of their UK suppliers, and notified them to ECHA in conformity with Article $38 \mathrm{REACH}$, such obligation will no longer apply - however 'in exchange' they will be obliged to register. In their own registrations, they will have to include any separate own uses.

\section{Evaluation}

If, upon Brexit, UK manufacturers/importers are relieved from their obligation to register and the 'no data no market' principle no longer applies to them, registration as a whole will become obsolete. As already illustrated above, UK manufacturers/importers will lose their status as registrants. ${ }^{24}$ Accordingly, they can no longer be the addressees of evaluation decisions and therefore can no longer be involved in such procedures (the provisions of Article 50 et seqq REACH apply only to registrants or downstream users).

As a consequence, UK manufacturers/importers will also be relieved of other obligations to comply with additional information requirements in relation to dossier evaluations (regarding testing proposals or in compliance auditing procedures) and in substance evaluations.

The same must apply, in our opinion, if the evaluation decision has already been issued to the UK manufacturer/importer at the time of Brexit but has not yet been complied with. In that case, the obliga- 
tion to comply no longer applies because the UK manufacturer/importers is entirely outside the scope of application of the REACH Regulation. Nothing else can apply with regard to the provisions of Article 50 paragraphs (2) and (3) of the REACH Regulation from which one might deduce that giving up the activity of manufacturing or importing following an evaluation decision does not entail a release from the obligation to comply with such a decision. In these cases, the former manufacturer/importer remains within the scope of application of the REACH Regulation.

It follows from the foregoing that, after Brexit, UK manufacturers/importers can no longer be made to participate in the costs of compliance with the evaluation decision. The remaining parties involved will have to share the costs among themselves. However, only in accordance with statutory REACH rules. If something else has been agreed in consortium agreements or SIEF contracts, such provisions shall be not affected.

Therefore, problems might arise in all consortia or SIEF in the event that a UK manufacturer/importer is 'prominently' involved in evaluation procedures or is even the lead registrant. ECHA must ask itself early on whether it still may, and still wants to, charge UK manufacturers/importers - in any case it will no longer be able to exclusively charge the UK manufacturer/importer. Equally, the business partners of UK manufacturers/importers in consortia and in SIEF will have to take precautions by way of mutual agreements and contractual arrangements.

\section{Authorisation}

For UK manufacturers/importers, the duty to obtain authorisation for their uses of SVHC, that are listed in Annex XIV, ceases to apply to them, and to downstream users, as they formally lose this status upon the Brexit.

For substances that are subject to authorisation and the sunset-date/expiry date (Article 58 paragraph (1) (c) (i) in conjunction with Article 56 paragraph (1) c) REACH) of which lies after the date on which the Brexit enters into force, UK manufacturers/importers will not even have to file an application for authorisation. Until then, they will be able to use the substances without authorisation. By contrast, for all substances in Annex XIV, the sunset-date of which is prior to Brexit, an application for authorisation will remain necessary if the UK manufacturer/importer wishes to continue using them until the date of Brexit and if he does not want himself or his customers to have to give up his/their use of them. In view of the costs and efforts involved with applications for authorisation and/or with accompanying applications for authorisation through authorisation procedures, UK manufacturers/importers ought to consider dispensing with an application for authorisation if the possible period of time between the sunset date/expiry date and the date of entry into force of Brexit is short and bridgeable. UK manufacturers/importers should discuss these aspects with their customers in order to ensure the unrestricted supply of products that are manufactured using substances that require authorisation. Whatever the case may be, it is recommended that EU customers approach their UK suppliers.

Authorisation procedures that are still ongoing on the date of Brexit will lose their cause and be obsolete because authorisation will no longer be required. It is unlikely that UK manufacturers/importers who filed the applications will be entitled to a refund.

Therefore, it might be advisable for the UK government to negotiate transitional provisions for their UK manufacturers/importers that would prevent such laborious and expensive precautionary applications for authorisation.

Authorisations that UK manufacturers/importers have already obtained will lose their validity and meaning. This applies particularly to provisions that relate to reviews of authorisations under Article 61 of the REACH Regulation.

A problem may arise for downstream users who, for own uses requiring authorisation, rely on the authorisations of their UK suppliers (Article 56 paragraph (2) REACH). At the date of Brexit they will require own authorisations. If authorisations already exist for UK suppliers or have already been applied for, downstream users are advised to submit an application for own authorisation in the EU in good time before the entry into force of Brexit to ensure that a positive decision will have been granted by the date of entry into force of Brexit. In cases in which the application date under Article 58 paragraph (1) c ii REACH is sufficiently far away to submit an own application for authorisation, downstream users should submit their own applications for authorisation from the start. 


\section{Restrictions}

Restrictions on substances listed in Annex XVII of the REACH Regulation that regulate production or use in the EU, will no longer concern UK actors from the date of entry into force of Brexit. However, restrictions on placing substances on the market may very well concern UK actors because either they themselves or their customers will be prohibited from placing the substances, or products containing such substances, on the Community market.

\section{Miscellaneous}

On the date of the Brexit, all Member States' rights to participate in the ECHA for the UK will of course cease to exist, too. For instance, the right to nominate a representative to the Management Board under Article 79 of the REACH Regulation will no longer apply. The same applies for the nomination of members in the Committees (Article $85 \mathrm{REACH}$ ) and in the Forum (Article 86 REACH).

Likewise, the UK will no longer participate in the various procedures that provide for a participation of the Member States (eg evaluation, Article $5^{1}$ REACH; granting authorisations, Article 64 REACH; identification of SVHC substances requiring autho- risation, Articles 58, 59 REACH). The ECHA will have to make corresponding provisions for its procedures.

\section{Conclusion}

The impact Brexit will have on REACH and CLP is manifold and will create problems on a large scale. The present article certainly does not identify, let alone think through, all possible problems. Some issues will only emerge in the course of time.

Nevertheless, the situation illustrated here shows two things: On the one hand there is an undeniable need for adequate transitional provisions which should be agreed upon in the ongoing negotiations or perhaps in the potential transitional phase. On the other hand, all parties involved are advised, despite all uncertainty about what the Brexit will really look like and when it will take place, to already address the possible consequences now, to monitor in which form Brexit will actually be implemented and, where possible, to take the necessary precautions as early as possible. The same applies for other regulations in substance and product law, eg the legislation on biocidal products, plant protection, or general product safety. In sum, Brexit creates problems we could do without but which we need to address. 